\title{
HIGH-CURRENT, HIGH-DUTY-FACTOR EXPERIMENTS WITH THE H' ION SOURCE FOR THE SPALLATION NEUTRON SOURCE*
}

\author{
M.A. Leitner", D.W. Cheng, R.A. Gough, R. Keller, K.N. Leung, \\ S.K. Mukherjee, P.K. Scott, M.D. Williams; LBNL, Berkeley, CA
}

\section{Abstract}

The ion source for the 1 MW Spallation Neutron Source (SNS) is required to provide $35 \mathrm{~mA}$ of $\mathrm{H}^{-}$beam current at $6 \%$ duty factor $(1 \mathrm{~ms}$ pulses at $60 \mathrm{~Hz})$ with a normalized rms emittance less than $0.15 \pi \mathrm{mm}$ mrad. The $\mathrm{H}^{-}$beam will be accelerated to $65 \mathrm{keV}$ and matched into a $2.5 \mathrm{MeV}$ RFQ. The ion source is expected to ultimately produce 70 $\mathrm{mA}$ of $\mathrm{H}^{-}$at $6 \%$ duty factor when the SNS is upgraded to 2 MW of power. For this application, a radio-frequency driven, magnetically filtered multicusp source is being developed at Berkeley Lab. The design of this new ion source is directed towards operation at the required high duty factor. Experimental results of the ion source operated in pure volume production mode (without cesium) and in hybrid mode (with cesium released into the source) are compared. An improved cesium dispensing system will be presented.

\section{ION SOURCE DESIGN}

A schematic of the SNS R\&D \#1 H ion source [1] is shown in figure 1 . The ion source is mounted inside a reentrant cylinder to move the ion source into the vacuum vessel. This enhances the vacuum pumping of the extraction gap. The source plasma chamber (10-cm-long by $10-\mathrm{cm}$-diam.) is made out of a copper cylinder with a back plate at one end and an outlet electrode at the other end. The plasma is confined by the longitudinal line-cusp fields produced by 20 rows of water-cooled, samariumcobalt magnets that surround the source chamber and transverse magnets on the back flange.

The hydrogen plasma is produced inductively by up to $65 \mathrm{~kW}$ of pulsed $2 \mathrm{MHz} \mathrm{RF}$ power. RF coupling is accomplished via a 2 1/2-turn, porcelain-coated (watercooled copper tubing) antenna connected to a matching network that matches the impedances of RF amplifier and

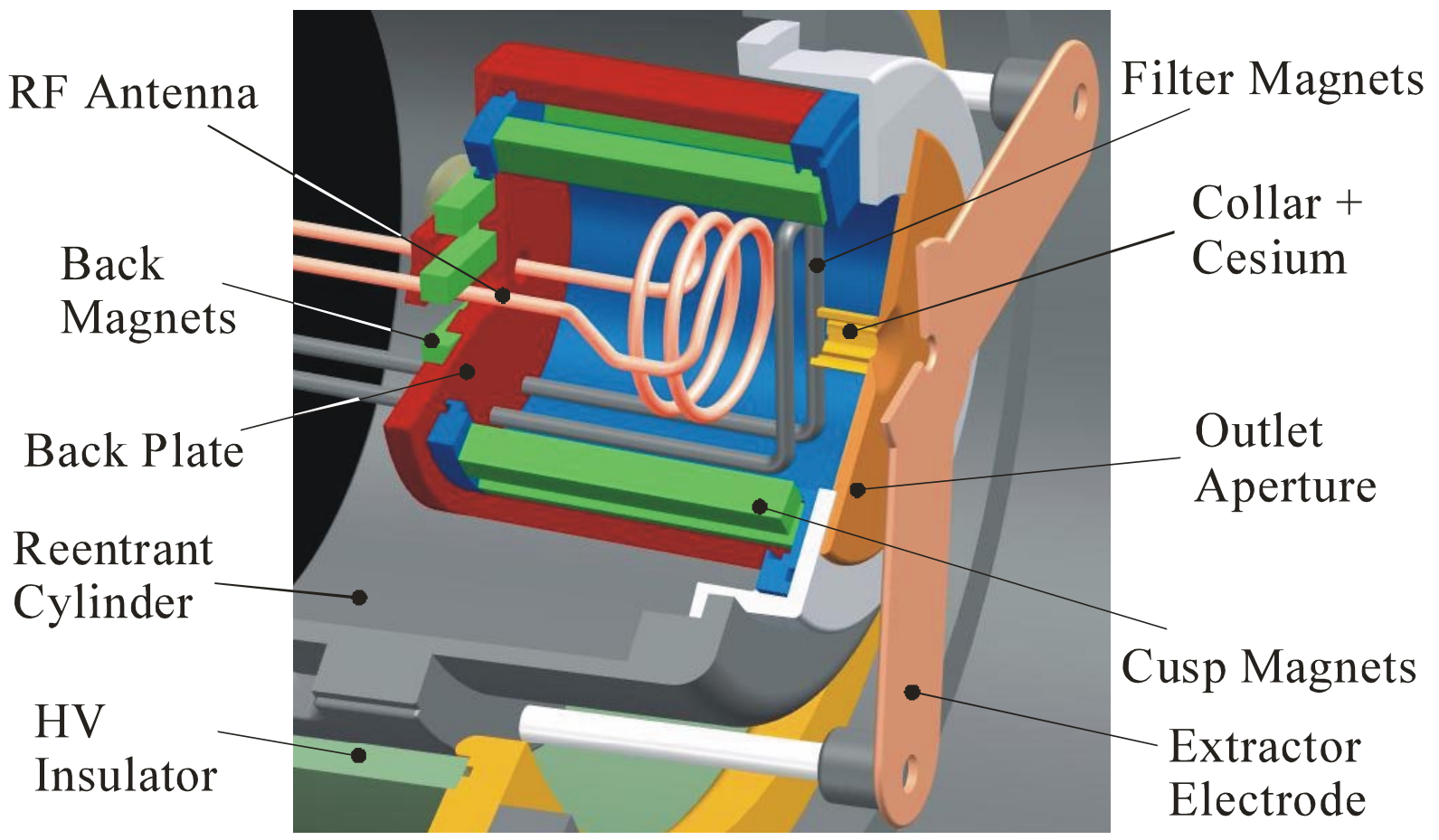

Figure 1: Schematic view of SNS R\&D \#1 H ion source.

Work supported by the Director, Office of Science, Office of Basic Energy Sciences, of the US Department of Energy under Contr. No. DE-AC03-76SF00098.

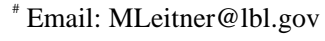


plasma. To minimize RF noise interference, the amplifier and matching-unit are installed on the ion source high voltage $(65 \mathrm{kV})$ platform, and are completely enclosed by a copper-plated steel shielding box.

Electrons supplied by a hairpin tungsten filament installed at the source back-flange assist starting of the ion source pulses. For cleaner discharge conditions, the filament can be replaced by an UV flash lamp or an inexpensive UV laser light system to produce primary photoelectrons.

A pair of water-cooled permanent magnet filter rods placed near the outlet electrode creates a narrow region of transverse magnetic field $(200 \mathrm{G})$ that divides the source chamber into the ("hot-plasma") discharge region and the ("cold-plasma") $\mathrm{H}^{-}$extraction region. The purpose of the hot plasma region is to produce excited $\mathrm{H}_{2}{ }^{0}(\mathrm{v}$ ") molecules, which can diffuse freely through the magnetic filter field. Hot electrons, which could easily destroy $\mathrm{H}^{-}$ions, are deflected by the magnetic filter field. Therefore, they cannot reach the extraction area.

Cold electrons are trapped, diffuse through the filter field, and produce $\mathrm{H}^{-}$ions in the outlet region by dissociative attachment to the excited $\mathrm{H}_{2}{ }^{0}(\mathrm{v}$ ") molecules. The removal of hot electrons is enhanced by installing a collar in front of the extraction hole. The deflected electrons are captured in this area. The optimum dimensions of the collar have been determined experimentally (15-mm-diam., 15-mm-long) for the $200 \mathrm{G}$ filter field.

The RF-driven source is operated at a continuous hydrogen gas flow of $20-30 \mathrm{sccm}$. Beam is extracted at $35-65 \mathrm{kV}$ across a single extraction gap and collected in a water-cooled double Faraday cup, which allows one to independently measure the $\mathrm{H}^{-}$current and electron content in the beam. The Faraday cup has been calibrated by using helium as the discharge gas. Since $\mathrm{He}^{-}$ions are extremely difficult to form, no current should be measured in the $\mathrm{H}^{-}$ Faraday cup. This was verified with an extracted electron beam of several amperes of current.

\section{OPERATION WITHOUT CESIUM}

More than $36 \mathrm{~mA}$ of $\mathrm{H}^{-}$ion current can be extracted from the SNS R\&D \#1 ion source if no cesium is added. With proper tuning of the RF matching-section the e-to- $\mathrm{H}^{-}$ current ratio can be reduced to about 27 at the highest $\mathrm{H}^{-}$ current levels, but it can be as high as 50. Due to the high electron current ( 0.9 to $2 \mathrm{~A}$ ) in pure volume production mode, the duty factor is limited by the extraction power supply. If the power supply cannot deliver the beam power, the extraction voltage decreases during the beam pulse. As a result, the ion beam impinges on the extractor electrode because of perveance mismatch, and sparkdowns occur.
Table 1 summarizes the peak performance of the ion source:

Table 1: SNS R\&D \#1 ion source performance without cesium.

\begin{tabular}{|l|c|}
\hline H current & 36 mA \\
\hline $\mathrm{e}^{-}$current & $960 \mathrm{~mA}$ \\
\hline $\mathrm{e}^{-} / \mathrm{H}^{-}$ratio & $>27$ \\
\hline RF power & $63 \mathrm{~kW}$ \\
\hline Duty factor & $<0.25 \%$ \\
\hline Extraction voltage & $27 \mathrm{kV}$ \\
\hline Extraction gap & $4 \mathrm{~mm}$ \\
\hline Extraction hole & $3.5 \mathrm{~mm} \mathrm{radius}$ \\
\hline $\begin{array}{l}\text { Gas flow through } \\
\text { extraction hole }\end{array}$ & $12 \mathrm{sccm}$ \\
\hline
\end{tabular}

Imposed by extraction power supply

\section{OPERATION WITH CESIUM}

Installing a collar around the outlet aperture can reduce the electron portion in the extracted beam. In such an arrangement, a small cylinder (15-mm-diam., 15-mmlong) is mounted on the outlet electrode, facing the plasma side (see Fig. 1). This collar can also be used to accommodate (inside radial grooves) tiny cesium getter-

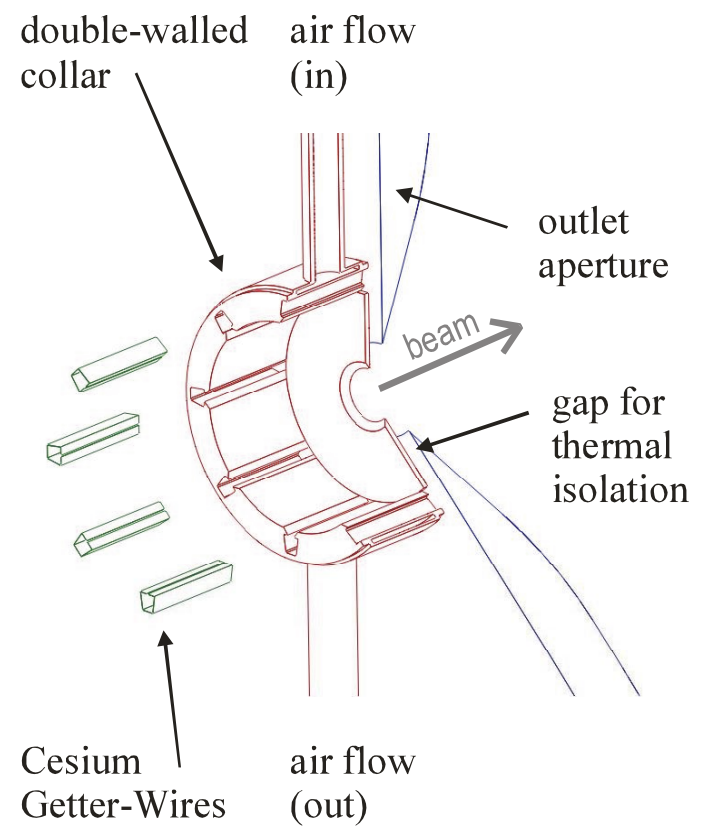

Figure 2: View of the new SNS $\mathrm{H}$ ion-source collar arrangement. Eight getter containers which slide into the slots located in the double-walled collar release a trace amount of cesium into this region. 
containers [2]. Such a configuration has been developed for the SNS H ion source, and is shown in figure 2.

The stainless-steel double-walled collar is thermally insulated from the rest of the ion source. Active cooling or heating - depending on the source duty factor - is possible by passing a temperature-regulated airflow through the collar jacket. The collar is massive enough to maintain a uniform temperature distribution along its inner surface. Cesium coverage of the collar surface lowers the work function, thus increasing the $\mathrm{H}^{-}$ion density in the plasma by surface production mechanism. The best source performance can be achieved at a surface temperature of around 200 degrees Celsius.

Uncooled, the new collar reaches a temperature of $\sim 400$ degrees Celsius at $50 \mathrm{~kW}$ RF input power at $12 \%$ duty factor. If cooled by pressurized air, the collar temperature could be reduced to 30 degrees Celsius. We have installed a heating element around the air input-line (outside the vacuum) to allow adjustment of the collar temperature independent from plasma heating (i.e. source duty factor).

This new cesium dispensing system allows very flexible source operation, which is not achievable with a cesium oven alone. In addition, since only trace amounts of cesium are dispensed into the ion source, no high-voltage spark-down problems occur in the extraction gap or in the downstream accelerator components.

After mounting the cesium dispensers inside the collar, maximum, stable source-performance can be achieved after only $1 / 2$ hour of source operation without special conditioning procedures. If the source is restarted up after previous operation (i.e. without breaking the vacuum) this time is reduced to $\sim 15$ minutes. As shown in figure 3 , $43 \mathrm{~mA}$ of $\mathrm{H}^{-}$have been achieved at $12 \%$ duty factor $(1 \mathrm{~ms}$

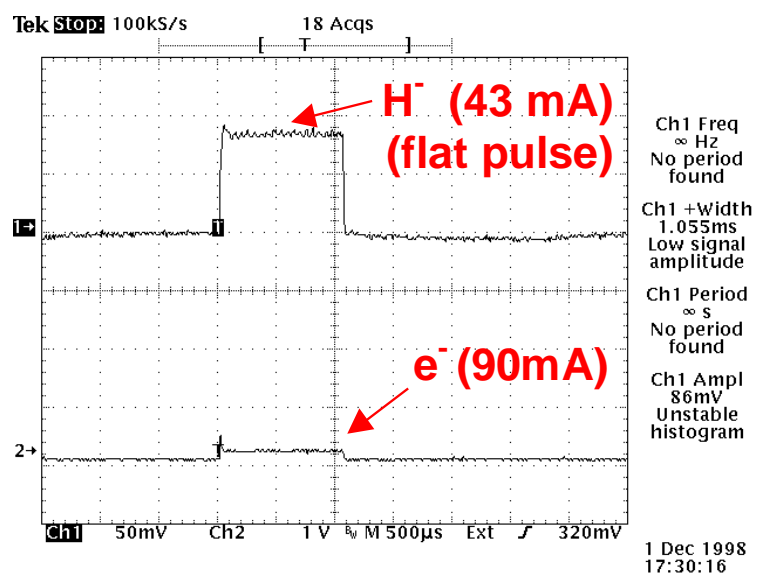

Figure 3: $43 \mathrm{~mA}$ of $\mathrm{H}^{-}$have been produced at $12 \%$ duty factor ( $1 \mathrm{~ms}$ pulse width) with trace amounts of cesium released into the ion source. At the same time, the extracted electron current has been reduced to $90 \mathrm{~mA}$. The ion beam pulse uniformity is within $1.2 \%(\sim 0.50 \mathrm{~mA})$, the pulse-to-pulse reproducibility within $0.6 \%(\sim 0.25 \mathrm{~mA})$. pulse length, $25 \mathrm{~kW}$ RF input power, $25 \mathrm{sccm}$ hydrogen gas-flow, extraction hole: $3.5 \mathrm{~mm}$ radius) with the described collar configuration. The ion beam pulse uniformity is within $1.2 \%(\sim 0.50 \mathrm{~mA})$, the pulse-to-pulse reproducibility within $0.6 \%(\sim 0.25 \mathrm{~mA})$. At the same time the extracted electron current has been reduced to $90 \mathrm{~mA}$, lowering the $\mathrm{e}^{-/} \mathrm{H}^{-}$ratio to a value of 2 . (During these experiments, the outlet aperture was electrically connected to the ion source body.) Only traces of cesium have been released into the ion source, since the collar always stayed below the temperature ( $\sim 500$ degrees Celsius) needed to start evaporation of the cesium getter wires.

\section{CONCLUSION}

Figure 4 compares the SNS R\&D source peakperformance without and with cesium released into the plasma chamber. By releasing cesium into the plasma chamber, the SNS ion-source requirements can be achieved at much lower RF input power. Furthermore, the extracted electron current is drastically reduced. Source start-up could be significantly simplified by introducing an improved collar design.

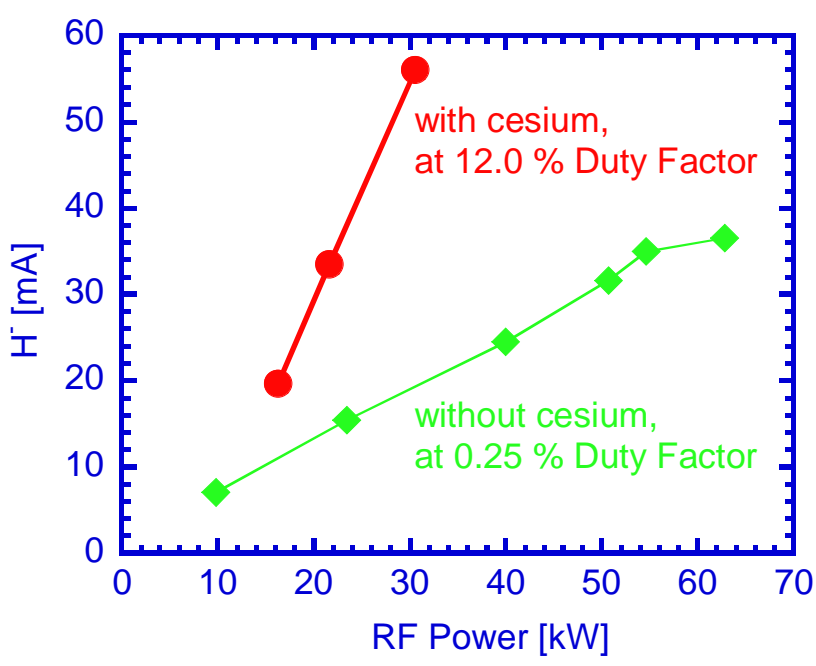

Figure 4: Comparison of SNS R\&D \#1 source performance without and with cesium released into the plasma chamber. In pure volume production mode the source duty factor is limited by the extraction power supply.

\section{REFERENCES}

[1] M.A. Leitner, R.A. Gough, K.N. Leung, M.L. Rickard, P.K. Scott, A.B. Wengrow, M.D. Williams and D.C. Wutte, "Development of the radio frequency driven $\mathrm{H}$ ion source for the National Spallation Neutron Source", Rev. Sci. Instrum. 69, 962 (1998)

[2] SAES Getters U.S.A., Inc., 1122 E. Cheyenne Mt. Blvd., Colorado Springs, CO 80906 (http://www.saesgetters.com) 